\title{
Pearls and Oy-sters: Symmetric Numbness and Paresthesia Due to Stroke-like Episode in an Adolescent Male With MELAS
}

Rachel Vassar, MD, and Nehali Mehta, MD

Neurology ${ }^{\circledR}$ 2021;97:1006-1008. doi:10.1212/WNL.0000000000012611

Mitochondrial encephalomyopathy, lactic acidosis, and stroke-like episodes (MELAS) syndrome is a mitochondrial condition with a wide range of neurologic complications, including migraines, seizures, and stroke-like episodes. This case report highlights a rare presentation of bilateral sensory changes related to MELAS and offers an opportunity to consider how a differential diagnosis may need to be modified in patients with underlying mitochondrial disorders. Neurologic symptoms in MELAS may defy classic localization patterns, and early neuroimaging is warranted.

\section{Pearls}

- Stroke-like episodes in mitochondrial encephalomyopathy, lactic acidosis, and stroke-like episodes (MELAS) can present with virtually any new neurologic symptom.

- L-Arginine is believed to decrease severity and risk of recurrence of stroke-like episodes in MELAS but does not necessarily prevent them.

- Patients with MELAS or other metabolic disorders can present with bilateral symptoms or imaging findings.

\section{Oy-sters}

- Any new neurologic symptom in a patient with MELAS must be considered to be a possible stroke-like episode until an alternative explanation is identified.

- Stroke-like episodes in MELAS can present in patterns that defy vascular territories.

\section{Case Report}

A 19-year-old man with mitochondrial encephalomyopathy, lactic acidosis, and stroke-like episodes (MELAS) syndrome was admitted to our institution for refractory nausea and vomiting. His neurologic examination was notable for a new left homonymous hemianopsia but was otherwise unchanged from previous examinations. Brain MRI demonstrated new diffusion restriction in the right occipital lobe, consistent with an acute stroke-like episode. His laboratory evaluation was notable for lactic acidemia. He was initiated on intravenous arginine to reduce the severity of the stroke-like episodes. ${ }^{1}$

Over the next 2 days, the patient demonstrated improvement in his nausea, vomiting, and lactic acidosis. On the third day of his admission, however, he developed new paresthesia and numbness starting in his left chest and arm, which then evolved over 24 hours to involve his face, including his mouth and tongue, and his right arm. The following day, his sensory symptoms had worsened and involved his entire body except for his scalp and groin. He noted difficulty with swallowing pills and speaking due to decreased sensation in his mouth. He denied headache, nausea, or vomiting and had no bowel or bladder symptoms.

\author{
Correspondence \\ Dr. Vassar \\ rachel.vassar@ucsf.edu
}

MORE ONLINE

Video 
His neurologic examination revealed an intact mental status. Cranial nerves were notable for preserved sensation in V1 but diminished sensation in V2 and V3 bilaterally. His strength examination was normal to confrontational testing. He had diminished sensation to light touch, pinprick, and temperature in his bilateral upper and lower extremities. Specifically, he reported decreased sensation to light touch in his chest, abdomen, bilateral arms, and legs circumferentially, more severe distally than proximally. Overall, his sensory deficits in the torso were more severe below T9 on his abdomen, but he had patchy, decreased sensation over his back without a clear spinal level in a nondermatomal distribution and sparing his groin. Joint position sense was intact. Coordination testing revealed mild dysmetria.

Reflexes were chronically absent. Based on his examination, no clear localization within the neuroaxis could be identified. $\mathrm{He}$ received scheduled intravenous fluids, ketorolac, and metoclopramide for presumed migraine but noted no improvement. An EEG was performed given a history of subclinical seizures but showed no epileptiform discharges. Ultimately, a repeat MRI brain and an MRI total spine were performed 2 days after the onset of sensory changes.

As shown in Figure 1, repeat brain MRI revealed new diffusion restriction in the bilateral postcentral gyri consistent with a new stroke-like episode likely explaining his sensory symptoms. See Video 1 for additional sequences of the brain MRI. He was given additional IV fluids, and his course of IV arginine was extended. Follow-up brain MRI 4 days later demonstrated interval development of new diffusion restriction in bilateral cerebellar hemispheres along with the evolution of

Figure 1 Axial DWI Sequence of Brain MRI Showing Restricted Diffusion in the Bilateral Somatosensory Cortices

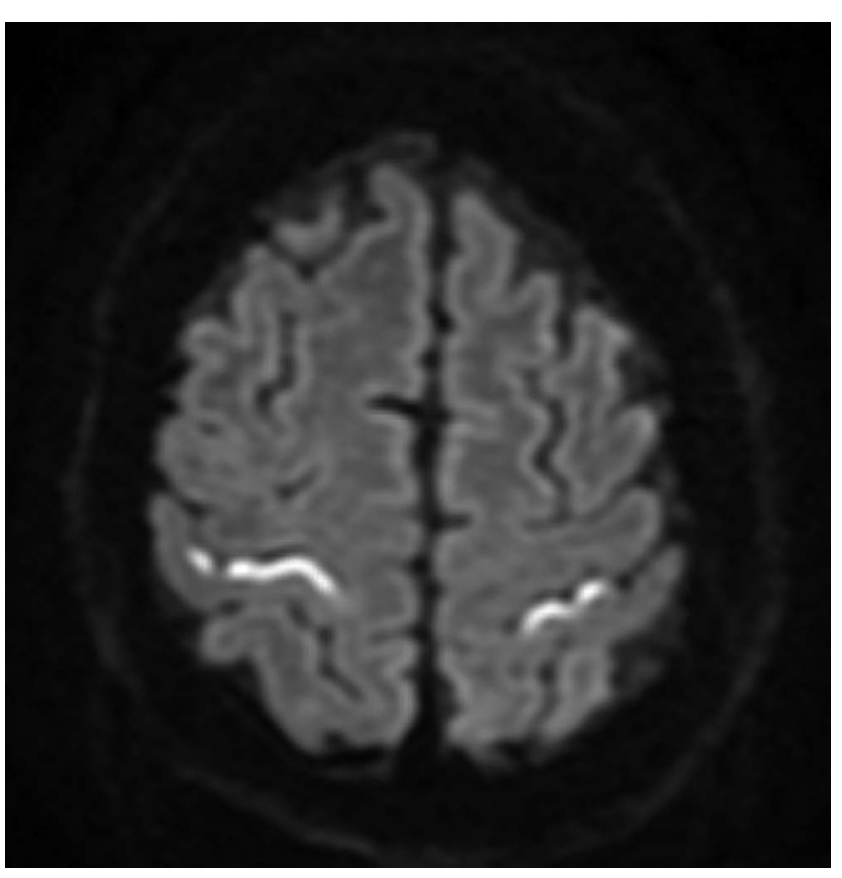

injury in the bilateral postcentral gyri. Three months later, brain MRI demonstrated resolution of most areas with previous injury with exception of persistent FLAIR hyperintensity in the bilateral occipital lobes. Clinically, he continues to suffer from whole body neuropathic pain requiring multimodal therapies, including acetaminophen, gabapentin, amantadine, memantine, morphine, clonidine patch, capsaicin cream, TENS unit, massage, and acupuncture. Four months since initial presentation, he remains hospitalized for inpatient rehabilitation.

\section{Discussion}

We are often taught that isolated bilateral sensory symptoms involving the face and body cannot localize to a structural brain lesion because this would require very restricted injury across multiple vascular territories and sparing most of the cortex. Migraine is frequently invoked in these patients who experience positive and negative full body sensory phenomena that include the mouth and do not map to a dermatomal distribution. This case demonstrates a rare case of stroke-like episodes involving the bilateral somatosensory cortices.

Patients with MELAS often develop lesions involving the occipital, parietal, and posterior temporal cortices. Particularly, distribution tends to favor posterior cortical regions, most commonly pericalcarine visual cortex but also the primary somatosensory cortex and tends to be asymmetric. ${ }^{2}$ However, symmetric lesions, such as this case, are becoming increasingly recognized in this syndrome and may occur in at least one-third of stroke-like episodes. ${ }^{3}$ The adjacent subcortical white matter can also be involved, but deep white matter is typically spared. Other less common regions affected include lacunar territories, basal ganglia, and cerebellum. ${ }^{4}$

Evidence for acute management of stroke-like episodes in patients with MELAS remains limited because of lack of randomized controlled trials. The most commonly studied treatment is L-arginine, a nitric oxide precursor that specifically targets the proposed mechanism of stroke-like episodes in MELAS. ${ }^{5}$ Stroke-like episodes are believed to result from impaired endothelial vascular relaxation leading to a mitochondrial angiopathy and subsequent vasoconstriction and hypoxemia in the affected brain regions. ${ }^{6}$ Nitric oxide synthase, found within endothelial cells, converts L-arginine to nitric oxide to allow for vasodilation. ${ }^{5}$ A small, unblinded study of 24 patients and several case reports have shown that $\mathrm{L}$-arginine therapy can be beneficial in reducing the severity and disability due to stroke-like episodes. ${ }^{1,7,8}$ Oral arginine administered in between stroke-like episodes may also reduce the frequency and severity of future stroke-like episodes. ${ }^{1}$ The 2015 consensus statement from the Mitochondrial Medicine Society recommends the use of arginine in patients with MELAS who are suffering from acute stroke-like episodes based on these data. ${ }^{9}$ Citrulline, another nitric oxide precursor, has also been proposed as a therapeutic modality; 
however, further studies are needed to elucidate its role in acute stroke-like episodes. ${ }^{10,11}$

Most lesions that develop during stroke-like episodes reduce in size or completely resolve on follow-up scans, particularly early in the disease, with a clinical correlation of complete functional recovery. ${ }^{4,5}$ Some lesions, however, may develop into chronic areas of cortical laminar necrosis. ${ }^{4}$ Eventually, patients with MELAS accumulate disability over time resulting in neurologic deterioration and premature death, although rate and severity of progression is widely variable. Juvenile onset of symptoms portends an overall worse prognosis. ${ }^{12}$

This case offers a reminder of the perplexing symptoms that can occur in patients with MELAS. Among patients who are susceptible to multifocal brain injury, such as those with mitochondrial conditions, any neurologic change- even those who seem to defy classic neurologic localization-may represent brain involvement and warrants expedited neuroimaging.

\section{Study Funding}

The authors report no targeted funding.

\section{Disclosure}

R. Vassar and N. Mehta report no disclosures relevant to the manuscript. Go to Neurology.org/N for full disclosures.

\section{Appendix Authors}

\begin{tabular}{lll}
\hline Name & Location & Contribution \\
\hline Rachel & Child Neurology Residency & Drafting/revision of the article \\
Vassar, & Program, Department of & for content, including medical \\
MD & Neurology, University of & writing for content; major role \\
& California San Francisco & $\begin{array}{l}\text { in the acquisition of data; study } \\
\text { concept or design; and analysis } \\
\end{array}$ \\
& & or interpretation of data \\
\hline
\end{tabular}

Appendix (continued)

\begin{tabular}{lll}
\hline Name & Location & Contribution \\
\hline Nehali & Child Neurology Residency & $\begin{array}{l}\text { Drafting/revision of the article } \\
\text { Mehta, }\end{array}$ \\
MD & Neuram, Department of & $\begin{array}{l}\text { writing for content; major role } \\
\text { California San Francisco }\end{array}$ \\
& $\begin{array}{l}\text { in the acquisition of data; study } \\
\text { concept or design; and analysis } \\
\text { or interpretation of data }\end{array}$ \\
& &
\end{tabular}

\section{References}

1. Koga Y, Akita Y, Nishioka J, et al. L-arginine improves the symptoms of strokelike episodes in MELAS. Neurology. 2005;64(4):710-712.

2. Bhatia KD, Krishnan P, Kortman H, Klostranec J, Krings T. Acute cortical lesions in MELAS syndrome: anatomic distribution, symmetry, and evolution. Am J Neuroradiol. 2020;41(1):167-173.

3. El-Hattab AW, Adesina AM, Jones J, Scaglia F. MELAS syndrome: clinical manifestations, pathogenesis, and treatment options. Mol Genet Metab. 2015; 116(1-2):4-12.

4. Xu W, Wen J, Sun C, Cao J, Li Y, Geng D. Conventional and diffusional magnetic resonance imaging features of mitochondrial encephalomyopathy, lactic acidosis, and stroke-like episodes in Chinese patients: a study of 40 cases. J Comput Assist Tomogr. 2018;42(4):510-516

5. Koenig MK, Emrick L, Karaa A, et al. Recommendations for the management of strokelike episodes in patients with mitochondrial encephalomyopathy, lactic acidosis, and strokelike episodes. JAMA Neurol. 2016;73(5):591-594.

6. Scaglia F, Northrop JL. The mitochondrial myopathy encephalopathy, lactic acidosis with stroke-like episodes (MELAS) syndrome: a review of treatment options. CNS Drugs. 2006;20(6):443-464.

7. Koga Y, Ishibashi M, Ueki I, et al. Effects of L-arginine on the acute phase of strokes in three patients with MELAS. Neurology. 2002;58(5):827-828.

8. Kubota M, Sakakihara Y, Mori M, Yamagata T, Momoi-Yoshida M. Beneficial effect of L-arginine for stroke-like episode in MELAS. Brain Dev. 2004;26(7):481-483; discussion 480.

9. Parikh S, Goldstein A, Koenig MK, et al. Diagnosis and management of mitochondrial disease: a consensus statement from the Mitochondrial Medicine Society. Genet Med Off J Am Coll Med Genet. 2015;17(9):689-701.

10. El-Hattab AW, Hsu JW, Emrick LT, et al. Restoration of impaired nitric oxide production in MELAS syndrome with citrulline and arginine supplementation. Mol Genet Metab. 2012;105(4):607-614.

11. El-Hattab AW, Emrick LT, Chanprasert S, Craigen WJ, Scaglia F. Mitochondria: role of citrulline and arginine supplementation in MELAS syndrome. Int J Biochem Cell Biol. 2014;48:85-91.

12. Koga Y. L-arginine therapy on MELAS. Article in Japanese. Rinsho Shinkeigaku. 2008; 48(11):1010-1012.

\section{Visit the Neurology ${ }^{\circledR}$ Website at Neurology.org/N}

- More article-based content on home pages

- Streamlined menus and navigation

- Enhanced blog sections for specialty areas

- Same experience on desktop, tablet, and mobile devices

- Improved article reading experience; links more evident (pdf, analytics, social media)

- Neurology ${ }^{\circledR}$ Clinical Practice initiative "Practice Current" global surveys will be accessible across sites

f Find Neurology ${ }^{\circledR}$ on Facebook: http://tinyurl.com/neurologyfan

Follow Neurology ${ }^{\circledR}$ on Twitter: https://twitter.com/GreenJournal 


\section{Neurology}

\section{Pearls and Oy-sters: Symmetric Numbness and Paresthesia Due to Stroke-like Episode in an Adolescent Male With MELAS \\ Rachel Vassar and Nehali Mehta}

Neurology 2021;97;1006-1008 Published Online before print August 10, 2021

DOI 10.1212/WNL.0000000000012611

This information is current as of August 10, 2021

\section{Updated Information \& Services}

References

Subspecialty Collections

Permissions \& Licensing

Reprints including high resolution figures, can be found at: http://n.neurology.org/content/97/21/1006.full

This article cites 12 articles, 3 of which you can access for free at: http://n.neurology.org/content/97/21/1006.full\#ref-list-1

This article, along with others on similar topics, appears in the following collection(s):

Migraine

http://n.neurology.org/cgi/collection/migraine

Mitochondrial disorders

http://n.neurology.org/cgi/collection/mitochondrial_disorders

Mitochondrial disorders; see Genetics/Mitochondrial disorders

http://n.neurology.org/cgi/collection/mitochondrial_disorders_see_gene tics-mitochondrial_disorders

MRI

http://n.neurology.org/cgi/collection/mri

Stroke in young adults

http://n.neurology.org/cgi/collection/stroke_in_young_adults

Information about reproducing this article in parts (figures,tables) or in its entirety can be found online at:

http://www.neurology.org/about/about_the_journal\#permissions

Information about ordering reprints can be found online:

http://n.neurology.org/subscribers/advertise

Neurology ${ }^{\circledR}$ is the official journal of the American Academy of Neurology. Published continuously since 1951, it is now a weekly with 48 issues per year. Copyright (C 2021 American Academy of Neurology. All rights reserved. Print ISSN: 0028-3878. Online ISSN: 1526-632X.

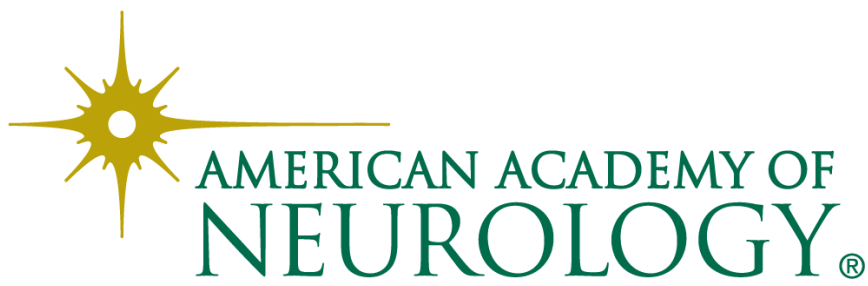

